\title{
Endoparasitic Insights of Free-Living Fin (Balaenoptera physalus), Humpback (Megaptera novaeangliae) and North Atlantic Right Whales (Eubalaena glacialis) from Eastern Canadian Waters
}

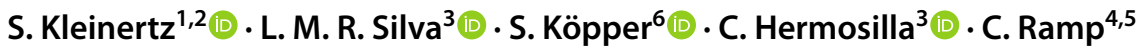

Received: 13 August 2020 / Accepted: 12 October 2020 / Published online: 31 October 2020

(c) The Author(s) 2020

\begin{abstract}
Purpose To date, little is still known on parasite infections affecting free-living large whale populations worldwide. Data presented should be considered as a baseline study for future monitoring surveys on endoparasites affecting whales, thereby enhancing investigations on impacts of zoonotic parasitoses not only on vulnerable or endangered baleen whale population health but also on public health.

Methods The presented study is a first report on gastrointestinal parasites infecting different free-living baleen whales inhabiting East Canadian waters using non-invasive methods. Individual faecal samples from fin ( $n=3$; Balaenoptera physalus), humpback ( $n=4$; Megaptera novaeangliae) and North Atlantic right whales ( $n=1$; Eubalaena glacialis) were collected without animal disturbance, within their natural habitats on an ecological expedition during annual surveys in summer 2017. Faecal samples were assessed by standardized diagnostic methods, such as sodium acetate acetic formalin (SAF) technique, carbol fuchsin-stained faecal smears, Giardia/Cryptosporidium coproantigen ELISAs and were applied for further identification.

Results Parasitological infections included three different potentially zoonotic parasite species, one protozoa (Entamoeba spp.) and two metazoans (Diphyllobothriidae gen. sp., Ascaridida indet.). No positive Giardia/Cryptosporidium coproantigen ELISA could be found in the studied whales.

Conclusion This study adds to the current knowledge of intestinal and zoonotic parasite infections of vulnerable to partly endangered free-ranging baleen whales. Only few or no parasitological studies exist for these whale species, usually dealing with only one dead specimen. We call for more research in this field especially for the importance of conservation of freeliving marine mammals using non-invasive methods.
\end{abstract}

Keywords Zoonoses · Endangered mammal species · Conservation

S. Kleinertz

sonja.kleinertz@uni-rostock.de

1 Aquaculture and Sea-Ranching, Faculty of Agricultural and Environmental Sciences, University of Rostock, Justus-von-Liebig-Weg 2, 18059 Rostock, Germany

2 Faculty of Fisheries and Marine Sciences, IPB University (Bogor Agricultural University), Jl. Agatis Kampus IPB Dramaga, Bogor, Indonesia

3 Institute of Parasitology, Justus Liebig University Giessen, 35392, Schubert Str. 81, Giessen, Germany

4 Mingan Island Cetacean Study, St. Lambert, QC J4P 1T3, Canada

5 Sea Mammal Research Unit, Scottish Oceans Institute, University of St. Andrews, St. Andrews KY16 8LB, Fife, UK

6 University of Bremen, Bibliothekstr. 1, 28359 Bremen, Germany

\section{Introduction}

Whale species, especially large whales are extraordinarily difficult to sample in the open ocean since they spend most of their time submerged, coming to the surface only for brief instants [1,2] or migrating over enormous distances [3, 4]. According to Hermosilla et al. [1] large whales are of special public interest and have been subjected to a variety of conservation measures, which could be better monitored and managed if physiological and pathophysiological data, such as parasite infections, could already be gathered from wild and free-ranging animals, instead of carcasses, within future studies [5]. Moreover, there are still no facilities for detailed examinations to accommodate whale species larger than $\sim 8 \mathrm{~m}$ of length [e.g., larger than killer whales (Orcinus orca)] in 
captivity which seriously hampers application of most classical parasitological diagnostic methods [2, 5]. Consequently, the present knowledge of diseases of large whales is still very scarce when compared to terrestrial vertebrate taxa [6].

Listed as endangered is the North Atlantic right whale (Eubalaena glacialis) under the Endangered Species Act (ESA) in 2005 [7] (also see IUCN Red List). Commercial whaling has severely depleted these whale species populations during past decades. More recently, direct and indirect anthropogenic impacts, namely in the form of vessel collisions and entanglement in fishing gear, have accounted for a lack of recovery [7]. With roughly 400 individuals still alive, the western North Atlantic population of right whales is one of the most critically endangered and vulnerable of any whale population in the world [8-10]. Within two centuries, this population could face extinction [11]. Therefore, Doucette et al. [12] as well as Fisheries and Oceans Canada [13] mentioned reports by the International Whaling Commission [14] and an expert panel [15], which strongly recommend, amongst others, to investigate the role of reproductive failure and declining health in impeding recovery of $E$. glacialis. Fin (Balaenptera physalus) and humpback whales (Megaptera novaeanglia) are listed differently from "least concern" to "vulnerable", respectively $[16,17]$.

Parasitic diseases are increasingly recognized for their profound influences on individual, population, and even ecosystem health [1, 6]. In fact, little is known about endo- and ectoparasites of any wild cetacean population [1, 6, 18-20]. In recent years, 'Emerging Infectious Diseases' (EIDs) [21] have been reported in several cetacean species and populations worldwide provoking large-scale die-offs, affecting reproduction, causing disfiguring skin diseases and, in some cases, zoonoses [22].

Within this study, large baleen whale species including fin whales, humpback whales and North Atlantic right whales were examined for their gastrointestinal parasites using noninvasive methods as reported elsewhere [1, 2, 5, 6, 19].

The present study aimed to identify gastrointestinal parasites of vulnerable or even endangered free-ranging marine mammal species like fin and North Atlantic right whales as well as to support the population status of least concerned humpback whales within their natural habitats by analyzing faecal samples, using non-invasive methods first introduced by Kleinertz et al. [20], in the North Atlantic Ocean to shed light on the health status of these protected and partly endangered large marine animals.

\section{Materials and Methods}

The Mingan Island Cetacean Study (MICS) examines baleen whales in the Gulf of St. Lawrence since 1979, the main research is the Jacque Cartier Passage $\left(49^{\circ} 54\right.$ $\left.41 \mathrm{~N}-64^{\circ} 3201 \mathrm{~W}\right)$. The Jacques Cartier Passage is located between the Quebec North Shore and Anticosti Island, the research area extends a bit further to the east and west, it is approximately between 63.0 and $66.0^{\circ}$ West and and between 49.6 and $50.3^{\circ}$ North. For this study, MICS collected faeces samples of fin, humpback and North Atlantic right whales (Balaenoptera physalus, Megaptera novaeangliae, Eubalaena glacilis), in July and August of 2017. All research was conducted under the approval of the Animal Welfare and Ethics Committee (AWEC) of the School of Biology, University of St. Andrews, UK.

Faecal samples were collected opportunistically. Inflatable boats approached individuals or a group of whales for photo identification. This procedure enabled the detection of faecal material floating on the surface when an animal defecated during its surfacing time (Fig. 1a, b). A self-built device consisting of an extendable handle bar and a piece of PVC pipe was used to collect the samples (Fig. 1c). At one end of the pipe, a piece of nylon stocking was attached with a hose clamp. This faeces collection device was used to amass as much material as possible. The device was lifted out of the ocean to lose most of the excess water (Fig. 1c). The filled nylon stocking was then placed in two zip lock bags to prevent leakage and stored on ice packs in a cooler. Back in the lab, the material from the nylon stocking was removed directly using a spatula. $25 \mathrm{ml}$ of the faecal sample was transferred into two $15 \mathrm{ml}$ tubes, which were topped up with $70 \%$ and $90 \%$ ethanol, respectively (Fig. 1d).

Coproscopical analyses were performed at Institute of Parasitology, Justus Liebig University Giessen, Germany, using the standard sodium acetate acetic acid formalin (SAF) technique with ethyl acetate $[23,24]$. The SAF technique was used for the detection of parasite eggs, cysts, sporocysts and oocysts within faecal material. Furthermore, coproantigen ELISAs (ProSpecT ${ }^{\circledR}$, Oxoid) were performed for the detection of Cryptosporidium spp. and Giardia spp. antigens in faecal samples. The parasitological identification of eggs was based on morphological characteristics referring to other reports and original parasite descriptions [25, 26]. Parasitological calculations (prevalence in \%) were made according to Bush et al. [27].

\section{Results}

Four out of eight examined whales proved to be parasitized (50\%). Parasitological analyses of faecal samples of freeranging baleen whale species revealed three different parasites: one (neozoan) protozoan taxa (Entamoeba spp.) and two metazoan parasite taxa (Cestoda: Diphyllibothrium cf. balaenopterae, Nematoda: Ascaridida indet.). [Entamoeba spp. (50\% prevalence), Diphyllobothrium spp. (25\% prevalence) and Ascaridida indet. (25\% prevalence)]. 
Fig. 1 Faecal sample collection: a, b: Fresh whale faeces on the ocean surface, c: Collection of faecal sample with a nylon device by boat, $\mathbf{d}$ : Preparation of faecal samples for analysis with ethanol

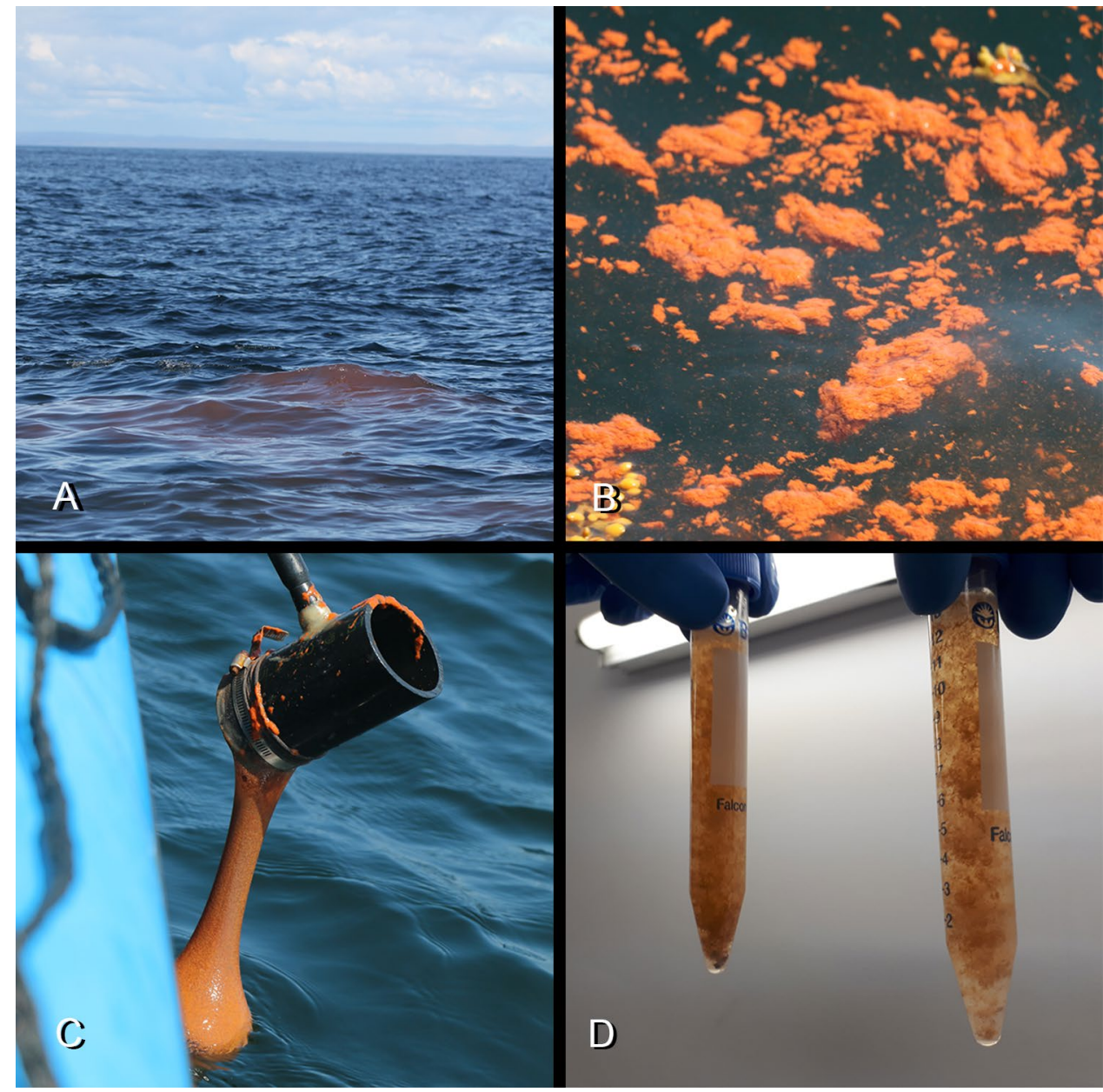

Neither trematode nor acantocephalan eggs were detected by microscopical examination of the SAF concentrated faecal samples. Furthermore, all samples proved negative for Cryptosporidium spp. and Giardia spp. performing coproantigen-ELISAs.

\section{Discussion}

During the past years, investigations on intestinal parasites of cetacean species usually rely on accidental strandings of single or small numbers of animals, on animals in captivity living or on dead specimens obtained from marine zoos [28]. By obtaining faecal samples directly from wild and free-ranging large whale species, these novel surveys bring the potential to unveal unique insights into the actual gastrointestinal parasite fauna of live, wild large whales ranging free within their natural environments [5, 20].

Due to the difficulties to obtain further appropriate samples, within the current study relatively low amount of faecal samples is considered. Nevertheless, all isolated parasite taxa within this study have zoonotic potential, even though presenting low prevalences. All detected parasite taxa have been reported already for fin whales [1,2], but not for the other species studied.

Entamoeba spp. infections in whale species have been only reported by Heckmann et al. [29] and Raga et al. [30] for dead bowhead whales, and by Hermosilla et al. [2] for free-ranging blue, fin and sei whales from the Azores, with relatively high prevalences $(64.7 \%)$. According to Hermosilla et al. [2], besides several non/low pathogenic species, such as Entamoeba coli, E. hartmanni, E. suis, E. polecki, and Iodamoeba bütschlii [31], there are species with high pathogenic and/or zoonotic relevance like E. histolytica.

In this study, we detected Diphyllobothriidae gen. sp. eggs (most likely Diphyllobotrium cf. balaeonopterae) in humpback whale faecal samples $(50 \%$ prevalence in humphback whale samples). Diphyllobotrium spp. infections in cetaceans are usually harmless [32,33], but in cases of high parasitic burdens, weakening and even death of parasitized hosts may be observed [20].

Ascaridida indet. eggs were detected in all four humpback whale faecal samples (overall prevalence of 50\%), but a morphological characterization to species level was not 
possible, since the eggs typify members of different genera, such as Anisakis, Pseudoterranova or Contracaecum. These genera have been reported frequently in marine mammals, which act as definite hosts to these species [34-36]. The ascarid nematode eggs most likely represent the genus Anisakis, given that the other genera mentioned rarely parasitize cetaceans [26] nematodes of the genera Anisakis are known to infect cetaceans as definite hosts [37].

In conclusion, this study adds to the current knowledge of intestinal parasite infections of vulnerable to partly endangered free-ranging baleen whales. Only few or no parasitological studies exist for these whale species, usually dealing with only one specimen, often from more or less degenerated carcasses [28, 38]. We call for more research in this field especially for the importance of conservation of free-living marine mammals, like whales in marine ecosystems under threat and for monitoring reasons of marine mammal health, encouraging long-term, worldwide and joint interdisciplinary sample efforts.

Acknowledgements We greatly acknowledge all MICS (Mingan Island Cetacean Study) team members and volunteers for all help around the field work and sampling collection. Thanks to the drone teams of TerreSky and Optik360. Field work (phoptographs) were taken under DFO permits QUE-LEP-001-2017, QUE-LEP-003-2018. Furthermore we want to express special thanks to Professor Anja Taubert for providing lab space and materials.

Author contributions SK (E-Mail: sonja.kleinertz@uni-rostock.de, sonja_kleinertz@yahoo.de): Sampling organisation, research idea, lab work and analysis for parasite identification, writing, correction and editing of manuscript. LS (E-Mail: liliana.silva@vetmed.uni-giessen. de): Supporting laboratory work and parasite identification, correction of manuscript and editing of manuscript. SK (E-Mail: svenja.koepper@gmail.com): creating and providing the photo plate, correction of manuscript. CH (E-Mail: carlos.r.hermosilla@ vetmed.uni-giessen.de): providing lab space and materials, correction of introduction, writing of abstract. CR (E-Mail: cr43@ st-andrews.ac.uk): Sampling organisation and collection, field support, taking and providing photos of area, sampling and whale species, providing of whale data, writing of material and method part, especially "study area", correction of manuscript.

Funding Open Access funding enabled and organized by Projekt DEAL.

Code Availability Not applicable.

\section{Compliance with Ethical Standards}

Conflict of interest On behalf of all authors, the corresponding author states that there is no conflict of interest or competing interests.

Human and Animal Rights This article does not contain any studies with human participants or animals performed by any of the authors.

Ethics Approval All research was conducted under the approval of the Animal Welfare and Ethics Committee (AWEC) of the School of Biology, University of St Andrews. UK.
Consent to Participate Not applicable.

Consent for Publication Not applicable.

Availability of Data and Material All available data are included in the manuscript.

Open Access This article is licensed under a Creative Commons Attribution 4.0 International License, which permits use, sharing, adaptation, distribution and reproduction in any medium or format, as long as you give appropriate credit to the original author(s) and the source, provide a link to the Creative Commons licence, and indicate if changes were made. The images or other third party material in this article are included in the article's Creative Commons licence, unless indicated otherwise in a credit line to the material. If material is not included in the article's Creative Commons licence and your intended use is not permitted by statutory regulation or exceeds the permitted use, you will need to obtain permission directly from the copyright holder. To view a copy of this licence, visit http://creativecommons.org/licenses/by/4.0/.

\section{References}

1. Hermosilla C, Silva LM, Prieto R, Kleinertz S, Taubert A, Silva MA (2015) Endo- and ectoparasites of large whales (Cetartiodactyla: Balaenopteridae, Physeteridae): overcoming difficulties in obtaining appropriate samples by non- and minimally-invasive methods. Int J Parasitol Parasites Wildl 4(3):414-420. https://doi. org/10.1016/j.ijppaw.2015.11.002

2. Hermosilla C, Silva LM, Kleinertz S, Prieto R, Silva MA, Taubert A (2016) Endoparasite survey of free-swimming baleen whales (Balaenoptera musculus, B. physalus, B. borealis) and sperm whales (Physeter macrocephalus) using non/minimally invasive methods. Parasitol Res 115(2):889-896

3. Silva MA, Prieto R, Jonsen I, Baumgartner MF, Santos RS (2013) North Atlantic blue and fin whales suspend their spring migration to forage in middle latitudes: building up energy reserves for the journey? PLoS ONE 8(10):e76507. https://doi.org/10.1371/journ al.pone. 0076507

4. Ramp C, Delarue J, Palsbøll PJ, Sears R, Hammond PS (2015) Adapting to a warmer ocean-seasonal shift of baleen whale movements over three decades. PLoS ONE 10(3):e0121374. https://doi. org/10.1371/journal.pone.0121374

5. Hermosilla C, Hirzmann J, Silva LMR, Brotons JM, Cerda M, Prenger-Berninghoff E, Ewers C, Taubert A (2018) Occurrence of anthropozoonotic parasitic infections and faecal microbes in free-ranging sperm whales (Physeter macrocephalus) from the Mediterranean Sea. Parasitol Res 117(8):2531-2541. https://doi. org/10.1007/s00436-018-5942-3

6. de Vos A, Faux CE, Marthick J, Dickinson J, Jarman SN (2018) New determination of prey and parasite species for northern indian ocean blue whales. Frontiers Mar Sci 5:104

7. National Marine Fisheries Service (2005) Recovery plan for the north atlantic right whale (Eubalaena glacialis). National Marine Fisheries Service, Silver Spring, MD

8. Clapham P, Young S, Brownell R (1999) Baleen whales: conservation issues and the status of the most endangered populations. Mamm Rev 29:35-60

9. Pettis HM, Rolland RM, Hamilton PK, Brault S, Knowlton AR, Kraus SD (2004) Visual health assessment of North Atlantic right whales (Eubalaena glacialis) using photographs. Can J Zoolog 82(1):8-19 
10. Pace RM 3rd, Corkeron PJ, Kraus SD (2017) State-space markrecapture estimates reveal a recent decline in abundance of North Atlantic right whales. Ecol Evol 7(21):8730-8741. https://doi. org/10.1002/ece3.3406

11. Caswell H, Fujiwara M, Brault S (1999) Declining survival probability threatens the North Atlantic right whale. Proc Nat Aca Sci USA 96(6):3308-3313. https://doi.org/10.1073/pnas.96.6.3308

12. Doucette GJ, Mikulski CM, King KL, Roth PB, Wang Z, Leandro LF, DeGrasse SL, White KD, De Biase D, Gillett RM (2012) Endangered North Atlantic right whales (Eubalaena glacialis) experience repeated, concurrent exposure to multiple environmental neurotoxins produced by marine algae. Environ Res 112:67-76

13. Fisheries and Oceans Canada (2020) Action plan for the North Atlantic Right Whale (Eubalaena glacialis) in Canada [Proposed]. In: species at risk act action plan series. Fisheries and Oceans Canada, Ottawa

14. International Whaling Commission (2001) Report of the workshop on the status and trends of western North Atlantic right whales. J Cetacean Res Manag 2:61-87

15. Reeves R, Clapham PJ (2001) Causes of reproductive failure in North Atlantic right whales: new avenues of research Report of a workshop held 26-28 April 2000, Falmouth, Massachusetts. In: Reeves RR, Clapham PJ (eds) Northeast Fish. Sci Cent Ref Doc Woods Hole, MA

16. Cooke JG (2018a) Megaptera novaeangliae. IUCN. https://doi. org/10.2305/IUCN.UK.2018-2.RLTS.T13006A50362794.en ((Accessed 09 Aug 2020))

17. Cooke JG (2018b) Balaenoptera physalus. IUCN. https://doi. org/10.2305/IUCN.UK.2018-2.RLTS.T2478A50349982.en ((Accessed 09 Aug 2020))

18. Raga JA, Balbuena JA, Aznar J, Fernandez M (1997) The impact of parasites on marine mammals: a review. Parassitologia 39(4):293-296

19. Kleinertz S, Christmann S, Silva LM, Hirzmann J, Hermosilla C, Taubert A (2014) Gastrointestinal parasite fauna of emperor penguins (Aptenodytes forsteri) at the Atka Bay. Antarctica Parasitol Res 113(11):4133-4139. https://doi.org/10.1007/s0043 6-014-4085-4

20. Kleinertz S, Hermosilla C, Ziltener A, Kreicker S, Hirzmann J, Abdel-Ghaffar F, Taubert A (2014) Gastrointestinal parasites of free-living Indo-Pacific bottlenose dolphins (Tursiops aduncus) in the Northern Red Sea. Egypt Parasitol Res 113(4):1405-1415. https://doi.org/10.1007/s00436-014-3781-4

21. Bengis RG, Leighton FA, Fischer JR, Artois M, Mörner T, Tate CM (2004) The role of wildlife in emerging and re-emerging zoonoses. Rev Sci Tech 23(2):497-511

22. Van Bressem MF, Raga JA, Di Guardo G, Jepson PD, Duignan PJ, Siebert U, Barrett T, Santos MC, Moreno IB, Siciliano S, Aguilar A, Van Waerebeek K (2009) Emerging infectious diseases in cetaceans worldwide and the possible role of environmental stressors. Dis Aquat Organ 86(2):143-157. https://doi.org/10.3354/dao02 101

23. Yang J, Scholten T (1977) A fixative for intestinal parasites permitting the use of concentration and permanent staining procedures. Am J Clin Pathol 67(3):300-304

24. Young KH, Bullock SL, Melvin DM, Spruill CL (1979) Ethyl acetate as a substitute for diethyl ether in the formalin-ether sedimentation technique. J Clin Microbiol 10(6):852-853

25. Dailey MD (2001) Parasitic diseases. In: Dierauf L, Gulland FMD (eds) CRC handbook of marine mammal medicine: health, disease, and rehabilitation. CRC Press, Danvers MA, USA, pp 357-379

26. Delyamure SL (1955) Helminthofauna of marine mammals (ecology and phylogeny). Izdatel'stvo Akiademii Nauk SSSR, Moscow

27. Bush AO, Lafferty KD, Lotz JM, Shostak AW (1997) Parasitology meets ecology on its own terms: margolis revisited. J Parasitol 83(4):575-583. https://doi.org/10.2307/3284227

28. Gibson DI, Harris EA, Bray RA, Jepson PD, Kuiken T, Baker JR, Simpson VR (1998) A survey of the helminth parasites of cetaceans stranded on the coast of England and Wales during the period 1990-1994. J Zool 244(4):563-574. https://doi. org/10.1111/j.1469-7998.1998.tb00061.x

29. Heckmann RA, Jensen LA, Warnock RG, Coleman B (1987) Parasites of the bowhead whale, Balaena mysticetus. Great Basin Nat 47(3):355-372

30. Raga JA, Fernandez M, Balbuena JA, Aznar FJ (2008) Parasites. In: Perrin WF, Thewissen HGM, Würsing B (eds) Encyclopedia of Marine Mammals. Elsevier, San Diego, pp 821-830

31. Matsubayashi M, Kanamori K, Sadahiro M, Tokoro M, Abe N, Haritani M, Shibahara T (2015) First molecular identification of Entamoeba polecki in a piglet in Japan and implications for aggravation of ileitis by coinfection with Lawsonia intracellularis. Parasitol Res 114(8):3069-3073. https://doi.org/10.1007/s0043 6-015-4509-9

32. Arundel JH (1978) Parasites and parasitic diseases of Australian marina mammals. In: House L (ed) The University of Sidney PostGraduate Committee in Veterinary Science. Course for Veterinarians, Sidney Australia

33. Geraci JR, St Aubin DJ (1987) Effects of parasites on marine mammals. Int J Parasitol 17(2):407-414

34. Colón-Llavina MM, Mignucci-Giannoni AA, Mattiucci S, Paoletti M, Nascetti G, Williams EH Jr (2009) Additional records of metazoan parasites from Caribbean marine mammals, including genetically identified anisakid nematodes. Parasitol Res 105(5):1239-1252. https://doi.org/10.1007/s00436-009-1544-4

35. Nadler SA, D'Amelio S, Dailey MD, Paggi L, Siu S, Sakanari JA (2005) Molecular phylogenetics and diagnosis of Anisakis, Pseudoterranova, and Contracaecum from northern Pacific marine mammals. J Parasitol 91(6):1413-1429. https://doi.org/10.1645/ ge-522r. 1

36. Mattiucci S, Nascetti G (2006) Molecular systematics, phylogeny and ecology of anisakid nematodes of the genus Anisakis Dujardin, 1845: an update. Parasite 13(2):99-113

37. Klimpel S, Palm H (2011) Anisakid nematode (Ascaridoidea) life cycles and distribution: increasing zoonotic potential in the time of climate change? In: He M (ed) Progress in Parasitology. Düsseldorf University Press, Düsseldorf

38. Oliveira JB, Morales JA, Gonzalez-Barrientos RC, HernandezGamboa J, Hernandez-Mora G (2011) Parasites of cetaceans stranded on the Pacific coast of Costa Rica. Vet Parasitol 182(24):319-328. https://doi.org/10.1016/j.vetpar.2011.05.014

Publisher's Note Springer Nature remains neutral with regard to jurisdictional claims in published maps and institutional affiliations. 